\title{
La flagelación como mecanismo punitivo en la jurisdicción especial indígena en Colombia ${ }^{1}$
}

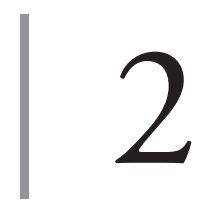

https://doi.org/10.21830/9789585284883.02

\author{
Paola Alexandra Sierra-Zamora ${ }^{2}$ \\ Vivian Lizbeth Arcos Cortés \\ Universidad Católica de Colombia \\ Manuel Bermúdez-Tapia ${ }^{4}$ \\ Universidad Privada San Juan Bautista \\ Lucas Joel Carreño Sua \\ Escuela de Aviación del Ejército
}

1 Este capítulo hace parte del trabajo colaborativo de dos proyectos de investigación: 1) "Desafíos contemporáneos para la protección de derechos humanos en escenarios de posconflicto desde enfoques interdisciplinarios - Fase II" del Grupo de Investigación "Persona, Instituciones y Exigencias de Justicia”, de la Universidad Católica de Colombia, registrado con el código COL0123247 y categorizado en A1 por Minciencias, y 2) "Perspectivas en Derechos Humanos y Derecho Internacional Humanitario para el Ejército Nacional de Colombia” del Grupo de Investigación en Aviación Militar de la Escuela de Aviación del Ejército, registrado con el código COL0077618 y categorizado en C por Minciencias. Los puntos de vista pertenecen a los autores y no reflejan necesariamente los de las instituciones participantes.

2 Abogada de la Universidad Católica de Colombia. Magíster en Derechos Humanos, Democracia y Justicia Internacional por la Universitat de València, España. PhD (c) del Programa de Derechos Humanos, Democracia y Justicia Internacional por la Universitat de València, España. Investigadora del Grupo de Investigación "Persona, Instituciones y Exigencias de Justicia”, de la Universidad Católica de Colombia. Orcid: https://orcid.org/0000-0002-3146-7418 - Contacto: pasierra@ucatolica.edu.co lica.edu.co

3 Estudiante de Derecho de la Universidad Católica de Colombia. Contacto: vlarcos18@ucato-

4 Abogado (magna cum laude) de la Pontificia Universidad Católica del Perú. Magíster en Derecho y PhD en Derecho por la Pontificia Universidad Católica de Argentina. Profesor-investigador de la Universidad Privada San Juan Bautista y profesor de la Facultad de Derecho de la Universidad Nacional Mayor de San Marcos. Orcid: http://orcid.org/0000-0003-1576-9464 - Contacto: manuel. bermudez@upsjb.edu.pe

5 Teniente Coronel del Ejército Nacional de Colombia. Especialista en Seguridad y Defensa Nacionales, Escuela Superior de Guerra "General Rafael Reyes Prieto”, Colombia. Especialista en administración de Recursos Militares para la Defensa Nacional y en Ciencias Militares para el Planeamiento, Centro de Educación Militar, Colombia. Profesional en Ciencias Militares, Escuela Militar de Cadetes “General José María Córdova”, Colombia. Orcid: https://orcid.org/0000-0002-7041-110X Contacto: lucas. carreno@buzonejercito.mil.co 


\section{Introducción}

Colombia, desde la Constitución de 1991, se declara como un Estado social de derecho. Dentro de otros avances de esta reforma constitucional, se presentó el pluralismo jurídico, con lo cual se revistió a las comunidades indígenas de una jurisdicción especial, dotándolas de este derecho en particular frente a los demás ciudadanos colombianos, con el fin de rescatar y no perder sus costumbres y tradiciones ancestrales.

Es necesario precisar que los usos y costumbres de los pueblos indígenas no son normas positivas, sino consuetudinarias. La justicia indígena, que actúa acorde con sus usos y costumbres, tiene como característica fundamental, inmersa en su identidad cultural, la oralidad de sus actuaciones y de sus pautas de control social interno, que se transmiten de generación en generación (Plaza, 2001, p. 21).

En correlación con lo anteriormente mencionado, es importante saber que esta nueva disposición que introdujo la Constitución de 1991 configuró un nuevo derecho para las comunidades indígenas, pero involuntariamente con este se abrieron puertas para la violación de derechos dentro las comunidades mismas, que exigen ahora que ese derecho que se les fue otorgado no sea violado. Tal es el punto que precisamente se evaluará en este capítulo, en relación con las limitaciones de ese derecho.

Los pueblos indígenas reclaman un reconocimiento que atraviese transversalmente temas de importancia nacional como son los de la tierra, la condición política, las formas de gobierno y administración de justicia, respeto a sus culturas, participación —en distintos niveles — de la toma de decisiones de gobierno. El punto es discernir hasta qué medida es conveniente introducir modificaciones sustantivas en las cartas magnas (lo que ya ha sucedido en la gran mayoría de los países latinoamericanos), que incorporan el tema del reconocimiento como una de sus garantías ciudadanas en la Constitución. (Ramírez, 2005, p. 4)

Del acápite anterior es de mayor relevancia la reclamación de las comunidades indígenas al respeto de sus formas de gobierno y administración de justicia, y esto se debe a los diferentes controles de legalidad ejercidos por el Estado colombiano frente a las formas de gobierno, puesto que se presentan 
violaciones internas a los derechos fundamentales, como el derecho a la dignidad humana, a la no tortura de todo ciudadano colombiano, de acuerdo con los tratados y convenios internacionales sobre derechos humanos.

Este es el problema que se ha suscitado dentro de las comunidades, puesto que se debe establecer las reglas de un debido proceso y precisar de mejor manera cuáles son los alcances de esta mal llamada justicia indígena que muchas veces se ha convertido en justicia por mano propia, llegando a consecuencias que constituyen una barbarie en esta sociedad y en este tiempo, tal parece que en vez de avanzar en cuestiones de justicia, hemos retrocedido muchos años atrás, en donde impera la violencia y la justicia por mano propia. (Vivar, 2015, p. 29)

Así se precisa que la flagelación es la contradicción propia de los fundamentos constitucionales de la "no tortura" y del derecho a la dignidad humana, puesto que se considera que estas penas son plenamente inhumanas, mientras que las comunidades indígenas consideran que su revestimiento legal y derecho de la jurisdicción indígena para acudir a este castigo es legítimo:

Nuestro, por haber nacido aquí mismo de las comunidades y la tierra americana, de una madre con quien debemos convivir y nunca explotar y degradar [...] porque es totalizante, como nuestra forma de pensar que involucra todo el conocimiento que adquirimos y manejamos [...] porque está vigente y es guía de nuestra conducta individual y colectiva, obligándonos a garantizar su permanencia en nuestro pensamiento, en nuestras lenguas, en nuestra organización social, en nuestras formas de educación y en nuestra reconstrucción económica y social [...] porque es preexistente, ya que nadie en el mundo puede negar nuestra existencia en estas tierras por miles de años en que constituimos nuestras sociedades. (Martínez \& Noguera, 2017, p. 16)

Da el anterior acápite cabe destacar la propiedad con la que las comunidades indígenas creen contar con prioridad sobre las normas, incluso cuando estas vulneran derechos fundamentales, dado que ellos se parapetan en la reconstrucción y el legado cultural que constituyen parte de una historia que no puede ser olvidada ni borrada.

Entonces, para comprender mejor lo que se va a desarrollar en este capítulo, es pertinente aludir a la primacía legal constitucional sobre cualquier ley. De acuerdo con esto, se propone como pregunta de investigación: ¿Es 
posible que se reconozca la potestad jurídica del Estado colombiano frente a la flagelación sobre los indígenas en la jurisdicción especial indígena?

Con respecto a esto, se aclara que el derecho consuetudinario o la ley natural de los pueblos indígenas, aunque reviste legalidad, debe contar con unos límites y una íntima relación con el cumplimiento de los derechos fundamentales contemplados en la carta política. Esto, en relación con la jurisdicción especial indígena, es un derecho llamado a ser subjetivo, entendido desde una órbita en la que es subordinado por la supremacía legal.

\section{Apuntes sobre la jurisdicción indígena en Colombia}

La jurisdicción indígena es uno de los temas más complejos de la ley colombiana, dado que aquella no tiene un sentido de mandato estricto sobre las comunidades indígenas y sus diferentes preceptos normativos, pues cuenta con un sentido propio de gobierno que limita el fuero de las leyes creadas para la población colombiana. En efecto, durante décadas se ha buscado reconocerles a las comunidades indígenas sus derechos, que les fueron limitados desde la época de la Corona, como se señala en el siguiente acápite, cuando se menciona que uno de los primeros episodios en los que se debatió sobre la autoridad de la Corona para juzgar a los indígenas tuvo lugar en 1496, cuando varios indígenas fueron condenados por sacrilegio al haber enterrado imágenes religiosas.

Es a partir de este punto que algunos hombres comienzan a concebir la idea de que los indios no deben ser juzgados, como posteriormente lo afirmó fray Gil Gonzales de San Nicolás: ni su majestad ni sus magistrados son competentes para juzgar a los indígenas (Mora, 2003, p. 14). Por lo anterior, podemos inferir que la jurisdicción colombiana dio lugar a la propia configuración de leyes indianas para su autogobierno. Como lo menciona Martiré, el derecho indiano surgió en el momento especial de la evolución del derecho europeo, en virtud de las características que le fueron impuestas por las necesidades de la Tierra Nueva, unas particularidades que le dieron fisonomía propia, con principios, normas y reglas de interpretación también particulares, que habilitan su propia personalidad (2003, p. 32). 
Por otro lado no se trataba solo de las costumbres de las nuevas tierras que se conquistaban y de adecuar las leyes que se tenían en su momento, sino que junto con la colonización de estas tierras nació la esclavitud de los indios, y con este un sistema de explotación y vulneración de los derechos humanos, que en su momento solo tenían cabida en la vida de quienes llegaban a explorar nuevas tierras y a adueñarse de absolutamente todo lo que se encontraba en estas, incluyendo así a las comunidades indígenas que se encontraran allí.

Análogamente se creó un régimen de explotación que recibió como nombre un eufemismo: encomienda. Vocablo que quería decir, en rigor, esclavitud bajo ciertas condiciones, pues acordaba el aprovechamiento de la mano de obra indígena por parte de los colonizadores a cambio de la evangelización y la enseñanza de las costumbres europeas. Contra este sistema de producción de riqueza se alzó la voz de protesta de Bartolomé de las Casas cuando, en 1514, liberó a los indios de su encomienda porque "se dolía de verlos padecer tantos agravios y sufrimientos sin que los merecieran" (Bartolomé de las Casas, 2011, p. 18).

Bartolomé de las Casas fue uno de los mayores opositores a la esclavitud de los indios, que se fundamentaba en una prolija base de segregaciones argumentadas, por ejemplo, en decir que los indios eran seres salvajes, faltos de razón, y que por esto debían estar bajo la servidumbre y el poder de un superior. Esto era totalmente contradictorio con el pensamiento humanista de Bartolomé de las Casas:

Los indios no son bárbaros por naturaleza, ni siquiera tienen la racionalidad disminuida, y por tanto son aptos para gobernarse. La naturaleza no hace nada en vano y no puede hacer a todo un pueblo incapaz de gobernarse. Además si fuera fallo de la naturaleza, lo sería de Dios que es su creador. Ciertamente los indios tienen algunos comportamientos salvajes, pero son susceptibles de modificación por la educación y evangelización para que puedan gobernarse y comportarse adecuadamente. (Bartolomé de las Casas, 2011, p. 14)

En esta medida y con referencia al avance constitucional que se tiene actualmente, Leyva —otro de los grandes defensores de los derechos de las comunidades indígenas en 1560 — afirmaba: "busco la supresión del servicio personal de los indígenas y desarrollo la institución de los resguardos que 
fueron el reconocimiento, por parte de la Corona española, del derecho de los indígenas a las tierras que ocupaban desde antes del descubrimiento" (citado por el Consejo Regional Indígena del Cauca, 1986, p. 10).

Así, en 1645, bajo el gobierno de Miranda Castillo de la Concha, se "dio cumplimiento de la Cédula Real que permitía la conservación de los usos y costumbres indígenas, estableciendo como límite que estas, no se encuentren en contradicción con las leyes de Castilla”, (Arbeláez, 1993). De esta forma se evidencia cómo el precepto normativo de limitar la jurisdicción o los derechos sigue siendo un patrón usado durante décadas, por cuanto una de las restricciones para poder acceder a ciertas garantías o derechos es que estas se encuentren siempre en una concordancia o una fina línea que respete los altos preceptos normativos que no deben ser vulnerados.

Sin embargo, y dado el consiguiente avance constitucional que se dio en 1828 por medio de la Resolución del 15 de octubre, con la cual se eximió a los indígenas del pago de cualquier clase de tributos, disposición que sigue vigente hasta hoy, a partir de esta época una larga lista de disposiciones legales se han expedido sobre las relaciones entre el naciente Estado y las comunidades indígenas.

La disolución de la Gran Colombia fijaría nuevos límites, con lo cual se dio la segregación de las comunidades limítrofes, lo que aumentó la desgracia de estos pueblos. Estas leyes buscarían la integración de las tribus al orden del Estado y su conversión a la vida civil. De acuerdo con esto, no se hablaba, como en la actualidad, de un autogobierno por parte de los pueblos indígenas, sino que, por el contrario, se discutía para tratar de recoger estas culturas y acomodarlas a las leyes que se tenían en su momento para no vulnerar ciertos derechos. De esta forma se buscaba que los pueblos indígenas hicieran parte del gobierno y de las prácticas legislativas que se tenían:

En 1890 y siguiendo con un esquema conservador, conforme al cual, se buscaba morigerar los usos y costumbres de los "salvajes", a través de las misiones y del aislamiento de las poblaciones indígenas, se expide el diez y seis de noviembre, la Ley 89, por medio de la cual se habla sobre el gobierno de los indígenas y las comunidades reducidas a la vida civil, que busca regular la vida de estas dentro de los resguardos; sería una ley de transición para facilitar la reducción, a largo plazo, de las comunidades, más originales a la civilizaz ción. Pero esta ley se convertiría en una de las únicas leyes especiales para las comunidades indígenas, que hoy en día tiene vigencia, a pesar de haber 
sido derogados o declarados inexequibles algunos de sus artículos. (Colombia, Corte Constitucional, Sentencia C-139/1996)

Sin embargo, un poco más de medio siglo después, en 1958, con la Ley 81, se creó el Instituto Indigenista Colombiano, que tendría a su cargo el estudio, el desarrollo y el progreso de las comunidades indígenas. El Instituto se estableció como un organismo consultor del Estado colombiano a través de sus recomendaciones. "A partir de este momento, la comunidades comenzaron a coordinarse y consolidarse en organizaciones regionales, que propendieron a la protección de las comunidades de su región” (Mora, 2003, p. 33).

De esta forma, el Estado colombiano empezó a ver desde otros ángulos el trato que se le debía dar a las comunidades indígenas para que fuesen sujetos de derechos dentro de una jurisdicción especial. Para ello se tenía que entender que estas debían tener su propio marco normativo, que tuviere relación con las costumbres y los enfrentamientos dentro del territorio de los pueblos indígenas. Fue así como surgió la Ley 52 de 1990, que dio lugar y formación a los principios de la Constitución Política de 1991.

En los anteriores acápites se hizo un breve recorrido histórico para poder llegar a lo que se puede denominar "la segunda etapa" de los derechos de las comunidades y pueblos indígenas, con la cual se abre paso el autogobierno de estas comunidades, que había tenido su inicio con el derrocamiento de la esclavitud indígena. Ahora bien, para poder hablar del periodo de la Constitución de 1991, es importante mencionar que la territorialidad sigue siendo uno de los puntos relevantes para las comunidades indígenas, ya que

el significado que tiene el derecho a la tierra para los pueblos indígenas es más complejo que el simple reconocimiento de su posesión colectiva. Incluye también el reconocimiento de un conjunto de garantías culturales, sociales y políticas que son inescindibles de los derechos territoriales. (Herreño, 2004, p. 241)

El territorio, en efecto, se debe estudiar desde dos perspectivas. En primer lugar, desde la cultura y el significado ancestral que para los indígenas tiene la madre tierra — como ellos la llaman—; y, en segundo lugar, desde la jurisdicción indígena. Esta última rige de manera bien específica, es decir, un indígena no puede ir a cualquier lugar a establecer sus prácticas de castigo sustentado en ella. Así, 
la cultura de las comunidades corresponde a una forma de vida que se condensa en un particular modo de ser y de actuar en el mundo, constituido a partir de valores, creencias, actitudes y conocimientos, que de ser cancelado o suprimido - y a ello puede llegarse si su medio ambiente sufre un deterioro severo- conduciría a la desestabilización y a la eventual extinción de dichas comunidades. (Colombia, Corte Constitucional, Sentencia T-380, 1993)

Por otra parte, no se puede considerar que una persona que tiene conceptos quizás totalmente distintos de juicios de lo que está prohibido y lo que se permite tenga que ser valorada dentro de una jurisdicción que está totalmente fuera de su alcance por su total desconocimiento. En efecto, una de las causas de la reforma constitucional de 1991 fue que la Constitución de 1886 era excluyente para diversas colectividades y fuerzas sociales, que quedaban allí desposeídas de cauces institucionales para expresarse e incidir en las decisiones del Estado. A consecuencia de esto, en la Constitución de 1991 se incorporó la participación de los indígenas en la conformación del nuevo pacto social y político. Como producto de este proceso, se reconoció a las autoridades indígenas en el artículo 246 de la Carta, así como la autonomía jurisdiccional dentro de su territorio ${ }^{6}$ conforme a las normas y procedimientos propios, a condición de no contrariar unas y otros la Constitución y las leyes de la república (Fernández, 2017, p. 22). Es por esto que la Constitución Política, en su artículo 241 da lugar a

connotaciones para las comunidades indígenas, pues les permite administrar justicia dentro de su territorio, conforme a sus normas y procedimientos establecidos; ese territorio abarca no simplemente el demarcado por sus resguardos, sino también el tradicionalmente ocupado por dichas comunidades. Ese derecho a administrar justicia tiene implícitas funciones legislativas, pues permite a las comunidades crear sus propias normas y procedimientos para ser aplicados dentro de su jurisdicción; cuando las comunidades indígenas deciden administrar justicia dentro de su territorio y emiten algún tipo de decisión, esa decisión tiene el mismo efecto jurídico que un fallo emitido por cualquier juez de la república dentro del Estado colombiano. (Rueda Carvajal, 2008, p. 38).

6 El concepto de autonomía es entendido como la capacidad de un grupo de establecer formas de organización social, económica y política propias, poseer el derecho a designar autoridades propias, diseñar sus relaciones en virtud de sus tradiciones y sus actividades económicas, preservar su lenguaje, poseer formas de educación y salud propias (Rojas et al., 1993, p. 37). 
Lo anterior tiene su fundamento en el artículo 246 de la Constitución Política cuando refiere que "las autoridades de los pueblos indígenas podrán ejercer funciones jurisdiccionales dentro de su ámbito territorial, de conformidad con sus propias normas y procedimientos, siempre que no sean contrarios a la Constitución y leyes de la República” (art. 45). Lo anterior es consecuente con el

Convenio 169 de 1989 de la OIT, sobre pueblos indígenas y tribales en países independientes, aprobado por Colombia mediante la Ley 21 de 1991. Este instrumento contiene el reconocimiento de un amplio catálogo de derechos de los pueblos indígenas como la autonomía, el territorio, la consulta previa, salud, educación, trabajo. Entre los derechos reconocidos por el Convenio, en el artículo 84 se consagra la obligación de los Estados de tomar en cuenta y favorecer la conservación de sus costumbres o su derecho consuetudinario y sus instituciones propias. El artículo 95 establece la obligación de respetar los métodos a los que los pueblos indígenas recurren tradicionalmente para la represión de los delitos cometidos por sus miembros. Por su parte el artículo 106 obliga a los Estados a que, cuando se impongan penas a los indígenas, sean tomados en cuenta sus aspectos sociales y culturales. (Arbeláez de Tobón, 2004, p. 8)

El anterior resumen histórico es de gran importancia para este capítulo, ya que ayuda a entender, en primera medida, la evolución legislativa que ha tenido Colombia en cuanto a las comunidades indígenas y, correlativamente, la función o el papel que cumplió y sigue cumpliendo el Estado colombiano para garantizar ciertos derechos a los indígenas, proporcionándoles su propia jurisdicción y sin olvidar que se deben mantener ciertas reglas y principios que son superiores a cualquier otra facultad.

\section{El fuero indígena ${ }^{7}$}

Para iniciar este apartado, es necesaria una clara comprensión del concepto de fuero al que se refiere la Constitución y la normatividad. Dicho concepto tiene relación directa con el anteriormente mencionado autogobierno o legisla-

7 Al hablar de justicia indígena o derecho indígena, nos referimos a aquellas prácticas resultantes de las costumbres de cada comuna, comunidad, pueblo y nacionalidad indígena, a través de las cuales las autoridades legítimamente elegidas por sus miembros regulan diversos ámbitos de las actividades, relaciones sociales y todo tipo de conflicto que se desarrolle dentro de su comunidad (Flores, 2011, p. 4). 
ción indígena, conceptos que, a su vez, varían y adquieren cierta ambivalencia en cada sistema normativo o jurídico (Bermúdez-Tapia, 2011). De hecho, esta situación ha requerido un pronunciamiento judicial hasta el punto de tener que evaluar la propia categoría jurídica detallada en la Constitución:

En tales términos, el fuero indígena, como derecho subjetivo de los miembros de las comunidades indígenas, por sí mismo, se convierte en un mecanismo de preservación étnica y cultural de la nación colombiana, en tanto se conservan las normas, costumbres, valores e instituciones de los grupos indígenas dentro de la órbita del territorio dentro del cual habitan, siempre y cuando no sean contrarias al ordenamiento jurídico predominante. Por esta razón, es en virtud del fuero indígena que se habilita la competencia de la Jurisdicción Especial Indígena, y, en consecuencia, esta se constituye en el juez natural en un caso concreto. Por el contrario, cuando el sujeto procesado no sea titular del fuero indígena, debe concluirse que son los jueces ordinarios las autoridades competentes. (Colombia, Corte Constitucional, Sentencia T-208/19)

Como ejemplo de lo anterior, la legislación y el autogobierno adoptados por los jefes o las autoridades de estas comunidades comportan una equívoca relación de esta jurisdicción cuando adoptan medidas que sobrepasan y vulneran la Constitución Política de Colombia (Peña Chivatá et al., 2019). Si bien esta última no es una fuente directa para la ley indígena, sí cuenta con supremacía legal, perplejidad que es entendida desde un prisma distinto cuando es vista desde la norma que respalda y regula la jurisdicción indígena:

Las comunidades indígenas son verdaderas organizaciones, sujetos de derechos y obligaciones, por medio de sus autoridades, ejercen poder sobre los miembros que la integran, hasta el extremo de adoptar su propia modalidad de gobierno y ejercer control social, el ejercicio de jurisdicción indígena no está condicionado a la expedición de una ley que la habilite, la constitución autoriza a las autoridades de los pueblos indígenas el ejercicio de sus funciones jurisdiccionales dentro de su ámbito territorial de conformidad con sus propias normas y procedimientos; Las Autoridades de los Pueblos Indígenas son entidades de carácter público especial, que ejercen funciones públicas administrativas, legislativas y jurisdiccionales; están constituidas por las Autoridades Tradicionales, Cabildos Indígenas y sus asociaciones, así como por otras instituciones propias, y ejercen el poder político, judicial, administrativo, espiritual o cultural al interior de los Pueblos Indígenas de conformidad con sus sistemas jurídicos propios. (Jarakirore, 2010, p. 18) 
Claramente, de acuerdo con el cariz de los documentos citados y del desarrollo histórico y jurisprudencial que ha tenido en Colombia lo que tiene todo lo relacionado con la autonomía de las comunidades o resguardos indígenas, se evidencia un claro conflicto frente a los derechos que son declarados como fundamentales, tanto nacional como internacionalmente, derechos que deben ser respetados incluso cuando se habla de una concesión de leyes a un territorio en especial o al propio autogobierno. Así,

la coexistencia de estos sistemas de derecho propio diferenciados frente al derecho estatal, en el marco de la nación, reconocidos oficialmente en la misma Constitución como legales y por ello oficializados, es consecuencia de la explícita decisión de los pueblos para mantener, no solo vivas sus instituciones, sino de su insistente aspiración social por configurar un nuevo orden capaz de hacer respetar sociedades culturalmente distintas; pero, ante todo, de buscar un espacio autonómico donde estos ciertos asuntos como lo relacionado con el ámbito del derecho, se solucionen dentro de su propia sociedad. Ha implicado que los jueces, cuando los casos entran a la jurisdicción ordinaria, tomen en cuenta en sus providencias los sentimientos, las opiniones y las obligaciones sociales derivadas de esas normas. El Estado, configurado por la existencia de varios sistemas jurídicos legales, oficiales, define —además del reconocimiento a los jueces competentes indígenas, para que actúen en el marco de su jurisdicción - la obligatoriedad de que se sometan a controles toda vez que sean demandados. (Sánchez, 2005, p. 15)

Por tanto, el fuero indígena en Colombia es un tema que debe ser estudiado minuciosamente, para poder entender qué límites son los que deben ser permitidos cuando se trata de la propia jurisdicción de un territorio. En este orden de ideas, se debe entender que

En la noción de fuero indígena se conjugan dos elementos: uno de carácter personal, con el que se pretende señalar que el individuo debe ser juzgado de acuerdo con las normas y las autoridades de su propia comunidad, y uno de carácter geográfico, que permite que cada comunidad pueda juzgar las conductas que tengan ocurrencia dentro de su territorio, de acuerdo con sus propias normas. La solución puede variar si la acción típica es cometida por miembros de pueblos indígenas dentro de su territorio, o si un indígena, de manera individual, incurre en ella afectando a quien no es miembro de su comunidad por fuera del ámbito geográfico del resguardo. En el primer caso, en virtud de consideraciones territoriales y personales, las autoridades indígenas son las llamadas a ejercer la función jurisdiccional; pero en el 
segundo, el juez puede enfrentar múltiples situaciones no solucionables razonablemente mediante una regla general de territorialidad. (Colombia, Corte Constitucional, Sentencia T-496/96)

Del elemento territorial ${ }^{8}$ y el personal, lo verdaderamente imprescindible es la forma en la que se comporta dicha jurisdicción o, mejor aún, la forma en la que actúa frente a las diferentes formas de castigo. De estas, es posible diferenciar aquellas cuyas comunidades actúan bajo el margen del derecho positivo y aquellas que ejecutan la pena bajo tradiciones y mitos.

En relación con lo anterior, decimos que existe una clara diferenciación entre un orden humano y un orden mágico-religioso. En el primer caso, se trata de normas creadas por los hombres, que implican arreglos o sanciones derivados de la operación de procedimientos que siguen un sistema segmentario, de compensación o centralizado, según la naturaleza de la conducta realizada o de los intereses en conflicto. En el segundo caso, por el contrario, lo que se persigue es el "control de las fuerzas de la naturaleza; entendida esta naturaleza dentro de la cosmovisión” (Duquelsky, 2003, p. 33). Por su parte, Moreno lo refiere de la siguiente manera:

Los indígenas resuelven litigios internos, que no pueden restringirse exclusivamente al territorio, sino que su alcance debe determinarse con criterios antropológicos. Los intereses comunitarios traspasan una zona circunscrita y pueden presentarse conflictos inclusive fuera de un espacio físico nacional o internacional. (2007, p. 3)

Lo anterior entiende un orden que complica en cierta medida el ordenamiento común, ya que algunas prácticas mitológicas o religiosas dentro de las comunidades indígenas pueden referir que el castigo o la pena de una conducta dentro de la comunidad debe ser llevada a cabo de manera ritual, para pagar de una u otra forma a sus dioses o a los caciques y jefes:

8 "Las poblaciones indígenas viven a menudo en las fronteras del país o, más exactamente, ocurre que las fronteras de los Estados pasan con frecuencia por el corazón mismo de los territorios indígenas y dividen a los grupos étnicos. Los Estados de la región, preocupados por asegurar su soberanía sobre tierras que usualmente están en litigio, han manifestado tradicionalmente la mayor hostilidad a todas las reivindicaciones indígenas que pudieran traducirse en la afirmación de una comunidad de cultura y de intereses entre poblaciones de un mismo grupo étnico que habite a ambos lados de la frontera" (Gros, 1993, p. 9). 
Respecto de la significación que tiene la pena para la comunidad y para el sujeto mismo, en no pocas ocasiones las penas tienen un sentido más bien purificador. Tal sucede por ejemplo, respecto de la aplicación de penas corporales como [...] los latigazos, el baño de agua fría y la ortiga. En ellas el infractor es castigado en presencia de toda la comunidad, a fin de que comprenda que su hecho ha afectado el equilibrio de todos, cada golpe (generalmente aplicado por algún familiar del penado o alguna persona a quien la comunidad le reconozca autoridad) va acompańado de un consejo (en este sentido es una pena correctiva). Luego, es ortigado y/o bañado con agua fría. En opinión de Borja, estos últimos no tienen carácter de pena, sino de verdaderos métodos rituales para la obtención de la confesión y el nacimiento del arrepentimiento. (Villegas, 2014, p. 219)

El problema no se centra en el castigo corporal como tal, sino en lo que este puede ocasionar: si bien para los indígenas es un medio para resarcir la pena, para el ordenamiento común e incluso para los tratados internacionales y los organismos de protección de los derechos fundamentales estos castigos pueden ser considerados como tratos crueles e inhumanos, en especial y con tintes aún más delicados, cuando estas penas recaen sobre menores de edad.

Para concluir, vale la pena tener presente que hay dos modalidades en las que las comunidades indígenas imponen sus penas. Por un lado, cuando actúan por su derecho propio e intervienen en cumplimiento de órdenes que están plasmadas en su tradición ${ }^{9}$ y se impone el resarcimiento de la pena por medio de diálogo y la conciliación entre la persona que cometió el delito y quien se ofendió. Por otro lado, se habla del resarcimiento del daño mediante una pena corporal que se impone de distintas maneras; en palabras de Lillo, "no todas las penas corporales constituyen tortura, y [...] para que adquieran tal entidad los sufrimientos producidos deben ser graves y crueles. La intensidad debe ser analizada a la luz de las circunstancias del caso, como la duración de la condena, sus efectos en la integridad física y moral del condenado, su

9 "El derecho indígena se fundamenta en una filosofía o religión de la dualidad armónica: así como el sol (hombre-padre) y la luna (mujer madre) se complementan y se unen, sin perder su diferencia y particularidad. Estos principios de equilibrio, interrelación y armonía entre hombre, naturaleza y sociedad se aplican también en las relaciones sociales. El conflicto entre personas causa, precisamente, un desequilibrio, una ruptura en estas relaciones. La justicia indígena busca entonces restablecer la armonía perdida. El inculpado, el denunciante, la autoridad y la comunidad juegan un rol importante en la restauración de este equilibrio" (Barié, 2008, p. 113). 
sexo, edad o condiciones de salud, e incluso el contexto sociopolítico en el que se practica" (2010, p. 10).

En analogía con lo anterior, la problemática es si se viola el derecho a la jurisdicción especial indígena que tienen las comunidades indígenas, cuando la jurisdicción ordinaria recurre a solucionar el problema de la violación de los derechos fundamentales, puesto que se entiende que no hay lugar a esta última, porque la pena corporal por parte de los indígenas sí está permitida en la medida en que no genere un trato cruel e inhumano que vulnere los derechos que son de alto rango constitucional.

\section{Los límites de la jurisdicción especial indígena colombiana}

El principio de diversidad étnica debe guardar una estricta relación con el bloque de constitucionalidad, es decir, aun cuando se permita la jurisdicción especial indígena y la creación de su propia normatividad, esta no puede violar valores ni derechos que han sido otorgados a todo ciudadano colombiano, sin importar su raza, religión y cultura. La identidad étnica, por lo tanto, no puede configurar una violación extensa de los derechos humanos fundamentales, tal como lo ratifica la Defensoría del Pueblo cuando relata:

Los límites de la jurisdicción especial de acuerdo con el artículo 246 de la C.P., se orientan: a) Las facultades jurisdiccionales de las autoridades indígenas se realizan conforme a sus propias normas y procedimientos. b) Las normas y procedimientos no deben contrariar los principios y disposiciones Constitucionales y legales vigentes. Es decir, que los límites de esta potestad de administrar justicia están determinados por los principios y derechos de carácter superior que emanan del sistema legal vigente. (Defensoría del Pueblo, 2014, p. 2)

Se estima, de esta manera, que el fuero indígena debe ser totalmente orientado a respetar los derechos humanos, inclusive si el respeto por estos desborda la estabilidad de las normas ya contempladas dentro de su sistema indígena, esto sin desconocer que los miembros de estas comunidades también son igualmente reconocidos como sujetos de derechos ya proclamados para todo colombiano. 
Así el Convenio 169 de la OIT, va en la misma línea del reconocimiento de los métodos de control propios de las comunidades indígenas, con el límite de que no se vulneren derechos fundamentales definidos por el sistema jurídico nacional ni los derechos humanos internacionalmente reconocidos. Señala que deberán establecerse procedimientos para solucionar conflictos que puedan surgir entre el derecho consuetudinario y los derechos humanos. La ratificación de este Convenio significa que los Estados firmantes admiten "el pluralismo jurídico interno" bajo el techo constitucional, al respetar formas de control y producción jurídica emitidas por instancias sociales. (Yrigoyen, 2000)

Se debe tener en cuenta, en consecuencia, que los derechos ratificados internacionalmente y por la Constitución Política deben sobreponerse a la jurisdicción indígena especial cuando en sus actuaciones se ataquen o violen preceptos de alto rango constitucional. Así, se reconoce el derecho de los pueblos y las comunidades indígenas a la libre determinación y, por lo tanto, a la autonomía para "aplicar sus propios sistemas normativos en la regulación y solución de sus conflictos internos, sujetándose a los principios generales de esta Constitución, respetando las garantías individuales, los derechos humanos" (Cabedo Mallol, 2004, p. 87).

Lo anterior determina una de las caras del prisma: la limitación de la jurisdicción indígena en la sujeción del castigo cuando se trata de derechos fundamentales, pero también se encuentra la posición que determina el respeto por la cultura y las etnias indígenas. Si bien se habla de jurisdicción especial indígena, es precisamente por un Estado multicultural, y lo que se busca con esta es que no se pierda dicha diversidad; por tanto, se habla de que algunas prácticas como la flagelación hacen parte de "una conducta correspondiente a una práctica ancestral [...], dentro de su cosmovisión propia" (Jaramillo, 2008).

Lo anterior se contrapone cuando autoras como Marrugo mencionan que:

Los derechos fundamentales constitucionales constituyen el mínimo obligatorio de convivencia para todos los particulares. Pese a que la sujeción a la Constitución y a la ley es un deber de todos los nacionales en general, dentro de los que se incluyen los indígenas, no sobra subrayar que el sistema axiológico contenido en la Carta de derechos y deberes, particularmente los derechos fundamentales, constituyen un límite material al principio de diversidad étnica y cultural y a los códigos de valores propios de las diversas comunidades 
indígenas que habitan el territorio nacional, las que, dicho sea de paso, estuvieron representadas en la Asamblea Nacional Constituyente. (2007, p. 43)

Para ilustrar la importancia de este capítulo y en especial de este acápite, que se relaciona con el límite de la jurisdicción especial indígena, es significativo relacionarlo con la justicia penal ordinaria, que trata temas como la flagelación o el daño de bienes jurídicos tutelados y permite su estudio para imponer la pena respectiva (Perafán, 1995).

En vigencia de la Constitución de 1991, y pese al reconocimiento del pluralismo jurídico de la nación colombiana consagrado literalmente en dicho texto, las sentencias del Tribunal instituido como guardián de la norma de normas admitieron — con reservas - la defensa del reconocimiento de la jurisdicción especial y la autonomía de las autoridades tradicionales (Álvarez Calderón \& Fernández-Osorio, 2018), sujetando tales derechos a la concordancia de las respectivas disposiciones con la Constitución y la ley.

La consagración en la Constitución del respeto por la diferencia, la pluralidad, la diversidad étnica y cultural, la calificación de las comunidades indígenas como sujetos colectivos, el reconocimiento de la jurisdicción indígena y de las autoridades tradicionales de estas comunidades, puede afirmarse que la consideración del indígena como sujeto de la ley penal nacional es inconstitucional, puesto que el juzgamiento de las conductas tipificadas en el respectivo código por parte de autoridades que hacen parte de la jurisdicción ordinaria, contrariaría los derechos fundamentales consagrados en los artículos constitucionales a los que se ha hecho referencia. (Becerra, 2006, p. 222)

Lo anterior es debatible desde varios aspectos, el primero de ellos tiene que ver con la violación de normas de alto rango constitucional, como se ha venido hablando en todo el texto, y el segundo tiene que ver con la jurisdicción especial indígena estudiada desde el aspecto territorial.

Así en principio los miembros de las comunidades indígenas gozan de un fuero especial, pero que eso no significa que siempre que un indígena realice una conducta punible, la jurisdicción especial indígena sea la competente para conocer del hecho, pues en este tema operan un fuero personal, "de acuerdo con el cual el individuo debe ser juzgado conforme a las normas y las autoridades de su propia comunidad", y otro fuero de carácter geográfico, "según el cual se permite que cada comunidad pueda juzgar las conductas que 
tengan ocurrencia en su territorio". Por ello concluye que para determinar a quién corresponde la competencia para investigar las conductas delictivas de los indígenas hay que atender las circunstancias particulares de cada caso, pues "puede optarse por la jurisdicción especial indígena o por la nacional, según se atienda al fuero personal o al fuero territorial”. (Colombia, Corte Constitucional, Sentencia C-370-2002)

Esta cita se enlaza con el artículo 33 del Código Penal colombiano ${ }^{10}$ que se refiere a la inimputabilidad de los sujetos, dentro del cual se hace referencia a la diversidad sociocultural, y debe entenderse desde la problemática o el deber de identificar si el indígena comprende la ilicitud de su conducta, en el momento en que este, como miembro activo del cabildo, castiga a otro miembro por algún acto y, con esta conducta, logra amenazar o dañar algún derecho fundamental.

En otro sentido, la Corte Constitucional se ha pronunciado en cuanto al límite de la jurisdicción especial indígena, mencionando la proporcionalidad de la pena y la actuación del sujeto y la ley indígena:

Esta Corporación ha sostenido reiteradamente que las sanciones impuestas al infractor deben guardar proporcionalidad con la conducta sancionada. Las autoridades jurisdiccionales gozan de un amplio margen de discrecionalidad en el uso del poder sancionador atribuido por la Constitución o la ley. No obstante, este poder no es ilimitado, debe ser razonable y dejar intactos otros valores jurídicos protegidos por el ordenamiento. Las sanciones o penas colectivas son contrarias al principio de que "nadie podrá ser juzgado sino conforme a leyes preexistentes al acto que se le imputable". Adicionalmente, la ley penal se erige sobre el principio de responsabilidad individual, que supone el juzgamiento del acusado y el respeto del principio de presunción de inocencia, presupuestos esenciales del poder sancionatorio del Estado o de los particulares que excepcionalmente ejercen funciones jurisdiccionales. (Colombia, Corte Constitucional, Sentencia, T-254/94)

Basta decir que se guarda en estricto sentido, una problemática entre la relación de la cultura ancestral indígena, sus distintos rituales y lo que la norma penal considera como la culpabilidad de la conducta.

10 Artículo 33 del Código Penal colombiano. "Inimputabilidad. Es inimputable quien en el momento de ejecutar la conducta típica y antijurídica no tuviere la capacidad de comprender su ilicitud o de determinarse de acuerdo con esa comprensión, por inmadurez psicológica, trastorno mental, diversidad sociocultural o estados similares". 
Respecto al principio de culpabilidad, este exige la constatación de responsabilidad subjetiva y la personalidad de las penas. En cuanto a la responsabilidad subjetiva, este principio resulta claramente afectado: "puede ser considerado delito el simple hecho de haber pisado un lugar sagrado, con independencia del conocimiento o intención. Y puede llegar a sancionarse por igual el homicidio doloso o el imprudente: solo importa el resultado producido" (Ferre, 2008, p. 39).

Esto desvela así la posibilidad de que se trasgredan los derechos humanos fundamentales, solo por prácticas que no generan una reinserción del sujeto a la comunidad, como lo encuentra posible el derecho penal Colombiano, o mejor lo plantea este en la aplicación de sus penas, en correspondencia con el delito.

\begin{abstract}
A pesar de lo anterior no sora decir que Colombia el país donde se ha explorado con mayor profundidad el tema de los límites de la aplicación del derecho indígena. Su Corte Constitucional se ha tenido que pronunciar sobre la constitucionalidad de algunas sanciones de carácter penal impuestas por las autoridades indígenas y que, según algunos, se instalaban en la prohibición de penas inusitadas o incluso en el concepto de tortura; la misma corte se ha pronunciado sobre varios casos que, sin afectar a los derechos fundamentales, tenían que ver con el tema de la compatibilidad entre el sistema jurídico indígena y el nacional. (Carbonell, 2003, p. 856)
\end{abstract}

De cualquier modo, no se debe olvidar que son una infinidad los problemas que emergen de la aceptación del pluralismo legal, puesto que es inherente de las comunidades étnicas el sentimiento de violación de sus derechos cuando el Estado colombiano entra a revestir un sistema que no es compatible con el suyo, con prácticas de los indígenas como la brujería. El tema ha producido ya importantes conflictos y controversias a lo largo del continente y ha sido objeto de conferencias internacionales (Fernández-Osorio, 2018). La actividad de la brujería, sancionada como actividad inaceptable en numerosas sociedades, pero que generalmente no es reconocida como delito (ni siquiera su existencia es admitida) en las legislaciones, ha documentado numerosos y dramáticos casos de homicidios cometidos por su causa. Tales homicidios, en cambio, son sancionados por el derecho penal nacional (Stavenhagen, 1990, p. 23).

Estos casos abren un nuevo debate, que se dibuja desde la perspectiva o el prisma contrario, y es cómo lo interpretan los indígenas. Para estos, al desco- 
nocer las normas y tradiciones nacionales con las que están construidas, les resultan totalmente perturbadoras o desequilibrantes, y este hecho es justamente lo que no logra entender el orden nacional cuando hace revisión de las normas indígenas. Por tanto, en lo que respecta al Estado colombiano, la brujería como tal no es lo que se sanciona, sino los delitos que se desprenden de ella:

Los derechos intangibles incluirían solamente el derecho a la vida, la prohibición de la esclavitud y la prohibición de la tortura. Dos son las razones que llevan a esta conclusión: en primer lugar, el reconocimiento de que únicamente respecto de ellos puede predicarse la existencia de un verdadero consenso intercultural. En segundo lugar, la verificación de que este grupo de derechos se encuentra dentro del núcleo de derechos intangibles que reconocen todos los tratados de derechos humanos, derechos que no pueden ser suspendidos ni siquiera en las situaciones de conflicto armado. (Colombia, Corte Constitucional, Sentencia, T-349/96)

En concordancia con todo lo interpretado ya en este capítulo, nace otro prisma u otra visión para entender: la diferencia entre el control de legalidad en diversos actos dentro de las comunidades indígenas y la violación al debido proceso dentro de las distintas jurisdicciones. Por ejemplo, el Estado colombiano no puede creer o pensar que la jurisdicción indígena tenga los mismos mecanismos o por lo menos las mismas solemnidades dentro de su forma de ley. Este caso se contempla en el ejercicio de la ley penal y su forma de custodia de las pruebas, cuestiones cuyo reconocimiento no se puede pedir por parte del sistema indígena, como tampoco las solemnidades del tipo "bajo la gravedad de juramento" ante la Biblia. Cuestiones como estas no pueden ser un imperio legal en ningún ordenamiento jurídico, por lo menos dentro de Colombia es la violación de principios y derechos de alto impacto constitucional, tal como lo ha manifestado el Estado: "Los jueces no pueden imponer el cumplimiento de requisitos e instituciones procesales que no se encuentran contemplados por un pueblo, pues ello equivaldría a la imposición de una específica cosmovisión, lo cual atenta contra el principio constitucional del pluralismo" (Colombia, Corte Constitucional, Sentencia T-523/97). Del mismo modo: "De exigir la vigencia de normas e instituciones rigurosamente equivalentes a las nuestras, se seguiría una completa distorsión de lo que se propuso el constituyente al erigir el pluralismo en un principio básico de la Carta" (Colombia, Corte Constitucional, Sentencia 1127/01). 
Así, para finalizar este acápite, es importante saber que

el pluralismo jurídico oficial y legal parte del reconocimiento de espacios marcados por nuevos referentes ligados a la inclusión que habrán de hacer otras autoridades y que son la base para superar modelos absolutistas. Para establecer esa cultura en torno a un pluralismo jurídico legal, que trascienda en un nuevo modelo de Estado, es imprescindible tener en cuenta el derecho ordinario y los otros derechos propios como parte de un sistema. La Constitución de 1991 reproduce el sistema jurídico monista, sólo que ahora bajo una forma distinta porque incluye en ese bloque, como aparato unificado, otros derechos indígenas diferentes al ordinario y lo hace en forma generalizada sin excluir a ninguno, lo cual garantiza al Estado la unidad y el principio de legalidad. Con este nuevo paradigma el Estado utiliza un nuevo mecanismo para reconocer que esos otros derechos, cuyos principios y procedimientos son distintos, comparten igual dignidad. || Se rompe así el monismo jurídico y se configura un mecanismo nuevo de integración formalmente jurídico de tipo igualitario en Colombia. (Sánchez, 2009, p. 40)

Se entiende, por consiguiente, que la flagelación es un acto que debe permanecer en el pasado, con la mayor inclusión posible y sin ningún tipo de distinción o preferencia, pues si la Constitución dota a todo colombiano de los mismos derechos, incluso para las comunidades indígenas, también debe revestirlas de deberes como el cumplimiento de ciertos derechos fundamentales, y más, tratándose de menores de edad.

\section{La flagelación como mecanismo punitivo frente a la legislación nacional}

Las múltiples manifestaciones del maltrato físico y psicológico de menores de edad es una de las grandes problemáticas que golpea al mundo en pleno siglo XXI, un siglo en el que ya no debería existir tal deshumanización, en el que el legado histórico, jurídico y cultural debería ser la directriz para no cometer los errores del pasado, y no un plano para retroceder. $\mathrm{Al}$ respecto, vale la pena traer a colación el comentario de Estrada Castro:

La violencia criminal u homicida contemporánea llevada a sus extremos se manifiesta como un tipo violencia, cuya finalidad no es ya el acto de quitar la 
vida, sino la destrucción del cuerpo marcado por el simbolismo de crueldad como forma de atentar contra la dignidad y la condición humana, la cual es conceptualizada en este artículo como violencia ontológica. El cuerpo es un discurso social y, junto con la mente y espíritu, un elemento constitutivo de lo humano, por lo que su desaparición, tortura, mutilación y desmembramiento, verifica la desarticulación psicológica y social de la condición humana, convirtiendo el cuerpo del cadáver en un mensaje deshumanizante del horror social. (2016, p. 24)

Es en este aparte en el que se complica hablar de la flagelación o cualquier tipo de maltrato físico como un medio de aprendizaje o escarmiento, como se había venido empleando durante décadas, pues de esta forma se sigue escribiendo una historia en la que se esclaviza el cuerpo humano. Tal es la directriz en la que la miseria del castigo y del delito se vuelven una sola, de forma que su presencia usurpa la conciencia de la humanidad y refleja el "Si lo haces pagas", y no un pago dinerario o algo que resocialice al causante, sino algo con lo que se da un impacto social, en el que el castigo será aún más grande que el daño causado a la comunidad.

De este modo, la crueldad y el sadismo, ya sean la fuente primera de la violencia, ya surjan con ocasión de ella, parecen convocar interpretaciones que desembocan en la idea o en la imagen de una fuerza psíquica o de un disfrute eventual desencadenados, por ejemplo, al destruir al otro con las propias manos, de manera asesina y sangrienta, lo cual se asemeja a un delirio. Tales fenómenos parecen proceder de la activación de pulsiones arcaicas, originarias, prohibidas y ocultas, que se liberarían en circunstancias que autorizan su manifestación (Wieviorka, 2003, p. 160).

Es por esto que la flagelación no debe seguir siendo culturizada, ni se debe plantear como un arraigo tradicional de las comunidades indígenas, aun cuando se trate de rituales, pues si algo no cambia entre el humano civilizado $y$ aquel que pertenece a otra forma de organización social es el concepto de castigo, de maltrato. Efectivamente, la historia de la humanidad inició con esto, con la guerra y el odio, tomando por su cuenta el cuerpo humano como la base del castigo, por cualquier acto que se considerase como violación a alguna regla, y es así como lo plasma el siguiente acápite al referirse a un tipo de gobierno. 
Una política deshumanizada y deshumanizadora refiere ciertos argumentos políticos que sobrepasaron la barbarie y la violencia con estrategias ínfimas de perversión y tiranía. Una política de Estado que se encargue del exterminio de sus opositores, ya sea por elementos étnicos, por salud pública, política o contrarrevolución indica la desesperanza y la falta de solidaridad y de compasión de los hombres hacia los "otros", estableciendo el mal radical y la reflexividad sobre la violencia, la crueldad y el terror. (Hernández, 2015, p. 15)

Lo anterior no se refiere solo a quienes están en condiciones óptimas para entender la legalidad de ciertos actos y lo que significa para ellos la barbarie, sino que contempla a toda la raza humana, a la que se conoció hace milenios, con reyes, con grandes monarcas, con imperios y aún a la civilización del siglo $\mathrm{XXI}$, con todo y los resguardos y comunidades indígenas, que tienen el castigo como forma ya mecanizada, por un arraigo histórico; como lo refiere Münch:

Anteriormente se hacía una ceremonia pública donde los acusados comparecían, a la que también se le llamó auto de fe. Los Castigos espirituales eran penitencias, ayunos, abstinencias y peregrinaciones. Las penas corporales podían Ser la muerte la flagelación, la cárcel y el exilio. Los penitentes eran montados a horcajadas en un burro, con una capucha en la cabeza donde se inscribían los delitos. Los reos estaban sometidos al ridículo público; mientras eran conducidos por las calles, el ejecutor los azotaba con golpes de correa. (Münch, 2010, p. 195)

De lo anterior es importante reconocer que no todo es horror y barbarie, pues la primera falta o problema en las comunidades indígenas no siempre se soluciona con azotes o maltratos físicos similares. Al igual que en el sistema sancionatorio colombiano, las comunidades indígenas también realizan la conciliación y los arreglos entre los jefes, mediante acuerdos de palabra y compromisos, pero en lo concerniente a nuestro trabajo es importante saber que

En muchos de los casos las resoluciones imponen penas físicas (como baño de agua fría, ortigazos, latigazos, caminatas descalzas sobre piedras o espinas, el arrodillamiento sobre piedrecillas o maíz mientras se carga peso en los hombros) y/o el pago de multas. Se trata de un escarmiento público que censura, tanto a nivel general la acción delictiva, como el acto particular cometido por un integrante de la comunidad. En palabras de los y las entrevistadas, es un ejercicio "ejemplificador" y que "infunde miedo". Así, de cara a la comunidad, aparecen como medidas que disciplinan y llaman al orden social. Pero, 
al mismo tiempo, sostienen que es un castigo "para que [el sentenciado] se componga y entre de nuevo en las reglas". Aquí, antes que un acto puramente punitivo, habría una apuesta "rehabilitadora". (Pequeńo, 2009, p. 83)

Además de la flagelación, existen muchos más castigos, como el cepo, una práctica bastante común de la ley indígena, que evidencia cómo las costumbres de las comunidades indígenas están arraigadas en procedimientos propios de la esclavitud (Barié, 2008). El castigo del cepo constituye un verdadero suplicio en el que las víctimas son mantenidas por uno, dos o más días con sus noches colgadas de las piernas, atrapadas del cuello o argolladas de las manos, sin permitírseles alimento alguno ni atender sus necesidades corporales. Esto genera un gran quebranto físico, razón por la que este castigo

era aplicado por las autoridades indígenas, en cabeza del misionero y del Gobernador indígena, por los delitos de robo y hurto de ganado mayor y menor, por heridas causadas, por adulterios y amancebamientos, muy a pesar de que el Código Penal, por entonces vigente, contemplaba penas específicas para cada uno de los delitos en referencia y, según el mismo Comisario, el juzgamiento de esos delitos correspondía a los jueces ordinarios. (López, 2005, p. 64)

Esto hace referencia al problema de la jurisdicción que se considera competente en cada caso, al respeto y a la no violación de un régimen multijurídico, ya garantizado por la Constitución Política colombiana, al dotar a las comunidades indígenas de una jurisdicción especial, pero en sí al límite de esta, puesto que

Argumentar que un asunto no se puede entregar a la jurisdicción especial indígena porque el homicidio es un hecho grave, es algo que no tiene validez jurídica alguna. La gravedad o no de un hecho, no se puede ni debe juzgar única y exclusivamente sobre la base de los parámetros culturales de la cultura, menos cuando bajo valores culturales ajenos; y que por tanto deben estar expresados con parámetros que válidamente sean justificados. Además, se está incurriendo en subjetivismos no propios de un debido proceso, pues lo que para una cultura pueda ser grave, es posible que para otra no. (Plaza, 2001, p. 25)

Los adelantos jurídicos o los avances que ha tenido la Constitución Política colombiana, como la inclusión de un Estado jurídico-cultural, no 
pueden generar un retroceso histórico, es decir, el hecho de que se brinde autonomía propia de una legislación no puede entenderse como la supresión de un mandato supremo — como lo es la carta política - para estas comunidades, puesto que esta consagra los derechos fundamentales que están por encima de cualquier sistema permitido en el Estado colombiano.

Colombia es un Estado social de derecho, lo que implica, sin duda, una nueva idea de aplicación de la justicia. El pensamiento del constituyente de 1991 concibió una actividad jurisdiccional eficaz, confiable y transparente a cargo de administradores de justicia de las diferentes jurisdicciones, comprometidos en proteger y garantizar a la persona los derechos sustanciales y las libertades consagradas en la Constitución Política y en la ley, con el objeto de alcanzar la convivencia social y la concordia nacional. (Bonilla et al., 2014, p. 11)

Por otro lado, uno de los puntos más discutidos es la igualdad en la que deben ser tratadas las diferentes jurisdicciones ya aceptadas por el Estado colombiano. En dicho punto, la premisa de igualdad entre iguales emerge con mayor fuerza, pues no se puede dotar de igualdad a una jurisdicción que no emerge de la mayor fuente (que es la carta política); es en esta última donde se fundan los límites de la primera. En otras palabras, se podría hablar de una igualdad entre distintas jurisdicciones indígenas, pero no de una igualdad entre la jurisdicción especial indígena y la jurisdicción ordinaria colombiana.

Esto dejó de ser llamado la normalidad, con la declaración de los derechos fundamentales y los límites al poder de cualquier Estado, y fue así como se incorporó a la humanidad una parte de la civilización. Lo anterior es la fuerza que da a entender que las comunidades indígenas, con sus mecanismos de penas y la barbarie de la flagelación, no pueden ser un retroceso en la historia y que el respeto a sus ancestros y a su cultura no pueden ser la pared que sostenga un acto teatral que conlleve solo a una faena y a un miedo imperioso, que pretendan impedir que se infrinja la ley. Al respecto, es claro que

El artículo 246 de la Constitución colombiana les permite a los pueblos indígenas juzgar a sus propios afiliados, pues reconoce a las autoridades indígenas y las reviste de facultades judiciales, además de que despliega el concepto de alteridad cultural, cosmogónica y social. Actualmente el Estado colombiano asume una jurisdicción ordinaria que se aplica a todos los ciudadanos del país. Reconoce la jurisdicción indígena con sus propios métodos, castigos, correc- 
ciones y sanciones. Y, finalmente, restablece un Estado unitario que coordina y controla las dos jurisdicciones, es decir, delega una autonomía pero limitada a las normas nacionales. (Pepinosa, 2012, p. 489)

Sobre esta limitación de la que se habla en el acápite anterior incursionan varios problemas, dentro de los que se configuran las penas impuestas por las comunidades indígenas —en sus resguardos y su jurisdicción- a menores de edad. Huelga decir que si ya es un problema que se violente el cuerpo humano de una persona que ya ha cumplido la mayoría de edad y que tiene por lo menos cierta posibilidad más que un menor de edad de defensa (FernándezOsorio \& Pachón Pinzón, 2019), mucho más problemático resulta cuando situaciones como la flagelación se presentan en niños, niñas y adolescentes.

Stavenhagen, por su parte, refiere que

muchos gobiernos consideran que la existencia de tales instituciones, diferentes de los mecanismos constitucionales o legales desarrollados por el Estado, constituye una forma de separatismo, una amenaza para la unidad nacional. La mayoría de los sistemas legales nacionales no reconocen las leyes e instituciones políticas indígenas. Por el contrario, pueden sostener que si ha de ser realidad la igualdad de todos ante la ley, tal como está establecida en los instrumentos internacionales sobre derechos humanos, entonces ningún grupo étnico en particular deberá tener el derecho a sus propias instituciones políticas y legales en el marco del Estado. Pero muchos observadores han señalado que la igualdad ante la ley es una ficción piadosa cuando se trata de pueblos indígenas y tribales, y que uno de los mejores instrumentos con los cuales cuentan estos pueblos para la defensa de sus derechos humanos es precisamente la validez de sus propias instituciones. (1995, p. 58)

Por otra parte, la esclavitud del cuerpo en cualquier circunstancia y forma es un problema que se ha venido esclareciendo y tratando de limitar y acabar con reformas y creaciones como la Declaración Universal de los Derechos Humanos y la Convención de los Derechos del Niño ${ }^{11}$ de 1990 por las Naciones Unidas. Colombia, en efecto, es uno de los Estados ratificados en

11 "Artículo 19. Los Estados Partes adoptarán todas las medidas legislativas, administrativas, sociales y educativas apropiadas para proteger al niño contra toda forma de perjuicio o abuso físico o mental, descuido o trato negligente, malos tratos o explotación, incluido el abuso sexual, mientras el niño se encuentre bajo la custodia de los padres, de un representante legal o de cualquier otra persona que lo tenga a su cargo" (Unicef, 1989). 
dicha Convención, lo que la hace inherente al cumplimiento de cada uno de los derechos allí contemplados.

Es mediante el poder para consentir y celebrar acuerdos que los Estados han creado un sistema político internacional y también han creado normas e instituciones para gobernar esas relaciones, es decir, es el derecho internacional que rige ese sistema. La autoridad fundacional del derecho internacional reside en el reconocimiento que los Estados han hecho como obligatorio para ellos y en el principio pacta sunt servanda, que se encuentra reflejado en la Convención de Viena sobre los tratados, al establecer que "todo tratado es obligatorio para las partes del mismo y debe ser respetado de buena fe". En la misma Convención en el artículo 27 se establece además que los Estados no podrán invocar su derecho interno para justificar el incumplimiento de las obligaciones derivadas de un tratado válidamente celebrado, todos los tratados de derechos humanos comportan para los Estados una serie de globalizaciones básicas. (Morlachetti, 2014, p. 32)

En correlación con lo anterior, se creó incluso la Convención contra la Tortura $^{12}$, que considera la flagelación como una forma de este suplicio, una de las más controvertidas por la ACNUDH (Oficina del Alto Comisionado para los Derechos Humanos), pues refiere que

De conformidad con los principios proclamados en la Carta de las Naciones Unidas, el reconocimiento de los derechos iguales e inalienables de todos los miembros de la familia humana es la base de la libertad, la justicia y la paz en el mundo. Teniendo en cuenta el artículo 5 de la Declaración Universal de Derechos Humanos y el artículo 7 del Pacto Internacional de Derechos Civiles y Políticos, que proclaman que nadie será sometido a tortura ni a tratos o penas crueles, inhumanos o degradantes. (ACNUDH, 1984)

Esto corresponde en gran medida al límite de la jurisdicción indígena en relación con la flagelación no solo de los menores de edad, sino de cualquier

12 "A los efectos de la presente Convención, se entenderá por el término "tortura" todo acto por el cual se inflija intencionadamente a una persona dolores o sufrimientos graves, ya sean físicos o mentales, con el fin de obtener de ella o de un tercero información o una confesión, de castigarla por un acto que haya cometido, o se sospeche que ha cometido, o de intimidar o coaccionar a esa persona o a otras, o por cualquier razón basada en cualquier tipo de discriminación, cuando dichos dolores o sufrimientos sean infligidos por un funcionario público u otra persona en el ejercicio de funciones públicas, a instigación suya, o con su consentimiento o aquiescencia. No se considerarán torturas los dolores o sufrimientos que sean consecuencia únicamente de sanciones legítimas, o que sean inherentes o incidentales a estas" (ACNUDH, 1984, art, 1). 
persona, sin importar su condición o incluso los actos cometidos por esta. Así lo respaldan la Convención contra la Tortura, la Declaración Universal de los Derechos Humanos y la carta política colombiana, que es norma prevalente para el cumplimiento de todas las comunidades y ciudadanos del país. El Estado, por su parte, garantiza que las decisiones de la jurisdicción indígena sean respetadas por las instituciones y autoridades públicas. Dichas decisiones estarán sujetas al control de constitucionalidad. La ley establecerá los mecanismos de coordinación y cooperación entre la jurisdicción indígena y la jurisdicción ordinaria (García, 2010, p. 34).

Así, en sintonía con todo lo mencionado hasta este punto, se entiende que no se vulnera la jurisdicción indígena, al no permitírsele el uso de la tortura en los procesos de castigos fundados en las comunidades indígenas, en cuanto se les reviste a los jefes de las comunidades de plenas facultades jurisdiccionales para juzgar a sus miembros, pero esto sin olvidar los mínimos exigidos constitucionalmente.

\section{El análisis de un caso de estudio}

Para ilustrar lo que se ha dicho y explicado en el contexto de este capítulo, es importante ver algunos ejemplos reales de lo que se vive en las comunidades indígenas que hacen uso de estas prácticas como parte propia de su cultura. Una de las modalidades de tradición en estas culturas que acuden al látigo es referida por Perafán:

Donde no existen circunstancias agravantes, el autor recibe un latigazo por cada una de las 25 autoridades comunales del Consejo gobernante. Los crímenes que merecen azotes en Toribio son aquellos considerados más serios: asesinato y robo. La sanción a menudo es aplicada conjuntamente con otras sanciones. El robo agravado podría causar hasta 5 latigazos por el alguacil, cinco ańos de trabajo en la empresa de la comunidad y la compensación por parte de los perpetradores a las familias de las víctimas, como en un caso en 1993 cuando un grupo de 8 hombres fueron responsables de 3 robos en la comunidad. (Perafán, 1995, p. 120)

Así mismo, el cepo, aunque no es tema concreto de este capítulo, sí está catalogado como otra de las manifestaciones de la tortura, y aunque es practicada ya por pocas comunidades, el Estado colombiano busca su abolición. 
Para una mejor explicación del cepo, la misma comunidad indígena chami de docabu lo expresa con sus propias palabras:

Dos pedazos de madera de 4" por 10" y 3,20 m de largo, con hasta veinte huecos cilíndricos de dimensiones pequeñas y grandes para acomodar los tobillos de personas de diferentes tamaños, de una manera tal que cada pedazo de madera forme la mitad de un cilindro, con el propósito de que cuando se juntan los dos pedazos de madera se formen los cilindros completos. Sobre el madero inferior se colocan las piernas, a la altura de los tobillos, para que el madero superior, al colocarse encima, coincidiendo con los huecos, atrape al preso dejándose flojo, con poca luz, el cual no se puede soltar porque por dichos cilindros no le caben los pies. Los maderos están unidos por un extremo con una bisagra y se aseguran por el otro con un candado... El cepo, utilizado continuamente, no es soportable por más de 24 horas. Por esta razón, muchas penas menores se castigan solamente con 12 o 24 horas de cepo. En penas más graves se pueden prescribir hasta ocho días de cepo, pero con periodos de descanso de una hora dos veces al día y con salidas adicionales a defecar y orinar. (Inksater, 2006, p. 32)

Los anteriores ejemplos son tan solo unos mínimos de tortura en relación con la forma de castigo usada en las comunidades indígenas (Ferré Olivé, 2009), con lo cual finalizamos este capítulo, porque es importante recordar que el objeto de la inclusión en un Estado plurijurídico siempre es avanzar tanto legal como socialmente, dando garantía y prevalencia a lo ya contemplado por la Constitución Política. Jamás se propenderá hacia un retroceso legal, cultural y social que se presente con la implementación de la tortura como castigo en las comunidades indígenas (Boaventura, 1987).

\section{Conclusiones}

Finalmente, es posible establecer que existen aún dificultades en disponer un sistema plurijurídico, cuando no se entiende el verdadero límite que debe ser impuesto a cualquier disposición legal. En este sentido, cuando se reviste de facultades a un colectivo como el de las comunidades indígenas, se debe establecer y constituir con preceptos claros en cuanto a la supremacía constitucional, que permite establecer los rangos vinculantes de derechos y deberes sin exclusión ni distinción alguna. 
Como elementos negativos en este proceso de reconocimiento de un sistema plural de sistemas normativos y jurídicos, podemos detallar algunas referencias puntuales:

a. Los pueblos indígenas no reconocen la Constitución Política como norma vinculante a priori, especialmente, en cuanto al respeto y el uso tradicional de sus propios valores normativos.

b. Se ha generado una serie de situaciones de confrontación entre dos sistemas normativos en Colombia, por lo cual es necesario establecer de forma clara la vinculación entre ambos, por cuanto los valores de legitimidad y legalidad no pueden ser excluyentes entre ambos sistemas.

c. El respeto por los derechos fundamentales de toda persona constituye un límite sobre la jurisdicción indígena, conforme lo estipula, por ejemplo, la Constitución Política peruana en su artículo 149 (Bermúdez-Tapia, 2017), patrón normativo que podría mejorar la percepción del conflicto entre jurisdicciones en Colombia.

\section{Referencias}

Álvarez Calderón, C., \& Fernández-Osorio, A. (Eds.). (2018). Hacia una gran estrategia en Colombia: construcción de politica pública en seguridad y defensa: Vol. 3. Pensamiento y cultura estratégica en Suramérica: un análisis de sus libros blancos de defensa. Escuela Militar de Cadetes "General José María Córdova".

Arbeláez de Tobón, L. (2004). La Jurisdicción Especial Indígena en Colombia y los mecanismos de coordinación con el Sistema Judicial Nacional. Consejo Superior de la Judicatura.

Arbeláez, A. (1993). Anotaciones sobre derecho indiano. Pontificia Universidad Javeriana.

Barié, C. (2008). Derecho indígena y medios alternativos de resolución de conflictos. Urvio, Revista Latinoamericana de Estudios de Seguridad, 3, 110-118. https://doi.org/10.17141/ urvio.3.2008.1077

Bartolomé de las Casas. (2011). Brevísima relación de la destrucción de las Indias. NoBooks.

Becerra, C. (2006). La jurisdicción especial indígena y el derecho penal en Colombia: Entre el pluralismo jurídico y la autonomía relativa. El Otro Derecho, 35, 213-136.

Bermúdez-Tapia, M. (2011). Análisis del manejo del desarrollo legislativo y temático de la consulta a pueblos indígenas. Revista de Análisis Especializado en Jurisprudencia, 39(4), 27-40.

Bermúdez-Tapia, M. (2017). La evaluación jurisdiccional de Derecho y condiciones de una comunidad campesina. Gaceta Civil \& Procesal Civil, 49, 63-76. 
Boaventura, S. (1987) Law: a map of misreading: toward a postmodern conception of law. Journal of Law and Society, 14(3), 279-302. https://www.jstor.org/stable/1410186

Bonilla, L., Corredor Gómez, N. G., \& Morales Moreno, L. F. (2014). Tensiones entre la jurisdicción especial indígena y la justicia ordinaria y como lo visibilizan los medios de comunicación colombianos [Tesis de pregrado]. Universidad Santo Tomás. https://repository.usta.edu.co/ handle/11634/330

Cabedo Mallol, V. (2004). De la intolerancia al reconocimiento del derecho indígena. Política y Cultura, 21, 73-93.

Carbonell, M. (2003). La constitucionalización de los derechos indígenas en América Latina: una aproximación teórica. Boletín Mexicano de Derecho Comparado, 36(108), 839-861.

Consejo Regional Indígena del Cauca. (1986). Legislación indigena: Comunidad Bienes Cauca.

Del Pueblo, D. (2014). Crisis humanitaria en Chocó: diagnóstico, valoración y acción de la Defensoría del Pueblo. Imprenta Nacional de Colombia. http://www.defensoria.gov.co/ public/pdf/crisisHumanitariaChoco.pdf

Duquelsky, D. (2003). Yo, Ovidio González Wasorna y el mito de la protección constitucional del derecho indígena. Cartapacio, 4(5), 3-44.

Estrada Castro, L. J. (2016). La escritura del horror en los cuerpos: violencia ontológica y simbolismo de crueldad. Estudios Politicos, 37, 57-80. https://doi.org/10.1016/j. espol.2016.02.003

Fernández, E. (Ed.). (2017). Justicia y pueblos indígenas: jurisprudencia, ritos, prácticas y procedimientos. Corte Suprema de Justicia.

Fernández-Osorio, A. (2018). El papel del Ejército Nacional de Colombia para el fortalecimiento de la paz en el posacuerdo con las FARC. En L. Cabrera, \& M. Corcione Nieto (Eds.), Aportes y retos en el posacuerdo: una perspectiva desde las ciencias militares. Escuela Militar de Cadetes "General José María Córdova".

Fernández-Osorio, A., \& Pachón Pinzón, R. (2019). Reconciliation perspectives in Colombia: Characterizing the 2016 Peace Agreement with the FARC. Revista de Relaciones Internacionales, Estrategia y Seguridad, 14(1), 31-56. https://doi.org/10.18359/ries.3356

Ferré Olivé, J. C. (2009). Diversidad cultural y sistema penal. De Jure: Revista Jurídica do Ministerio Público do Estado de Minas Gerais, 22, 23-42.

Ferre, J. C. (2008). Diversidad cultural y sistema penal. Revista Penal, 22, 33-42.

Flores, D. (2011). La justicia indígena y sus conflictos con el derecho ordinario. Equipo Jurídico INREDH.

García, F. (2010). Formas indígenas de administración de justicia. FLACSO.

Gros, C. (1993). Derechos indígenas y nueva Constitución en Colombia. Análisis Político, 19, 8-24. https://revistas.unal.edu.co/index.php/anpol/article/view/75176

Hernández, L. (2015). El terror en los orígenes del totalitarismo y la política de la muerte. Ciencias Sociales y Educación, 4(8), 43-60.

Herreño, Á. L. (2004). Evolución política y legal del concepto de territorio ancestral indígena en Colombia. El Otro Derecho, 31-32, 247-272. 
Inksater, K. (2006). Resolviendo tensiones entre derecho indígena y normas de derechos humanos a través del pluralismo juri-cultural transformativo [Tesis de maestría]. Universidad de Ottawa.

Jarakirore, D. (2010). Resguardo indigena la cristalina etnia embera chami con Resolución Noo. 113 del 21 de septiembre de 1993. Ministerio del Interior. https://bit.ly/2zp8exi

Jaramillo, E. (2008). La mutilación de clitoris a niñas emberas: un debate necesario. Servindi. https://www.servindi.org/node/41729

Lillo, R. (2010). El Convenio 169 de la OIT y la defensa penal de indígenas. Defensorías Regionales: Minuta Regional, 1, 3-23. https://bit.ly/36qrPJy

López, A. (2005). El Valle de Sibundoy: el despojo de una heredad. Los dispositivos ideológicos, disciplinarios y morales de dominación. Anuario Colombiano de Historia Social y de la Cultura, 32, 51-73.

Marrugo, N. (2007). Las mutilaciones sexuales de las niñas indígenas embera chami, el multiculturalismo y los derechos fundamentales. Justicia Iuris, 8, 41-44.

Martínez A., \& Noguera, D. (2017). Garantía de los derechos constitucionales de los pueblos indígenas en el multinacionalismo y el neoconstitucionalismo. Novum Jus: Revista Especializada en Sociología Jurídica y Política, 11(2), 19-51. http://dx.doi. org/10.14718/novumjus.2017.11.2.2

Martiré, E. (2003). Algo más sobre derecho indiano: entre el ius commune medieval y la modernidad. Anuario de Historia del Derecho Español, 73, 231-264.

Mora, D. (2003). Bases conceptuales de la jurisdicción especial indígena [Tesis de pregrado]. Pontificia Universidad Javeriana.

Moreno, C. (2007). Jurisdicción indígena. Reconocimiento de derechos, exigibilidad de obligaciones. Foro, Revista de Derecho, 8, 179-189. https://revistas.uasb.edu.ec/index.php/foro/ article/view/341

Morlachetti, A. (2014). La Convención sobre los Derechos del Niño y la protección de la infancia en la normativa internacional de derechos humanos. En F. Beltrão, J. Monteiro, B. Filho, J. Gómez, I. Pajares, E. Paredes, \& F. Zúñiga (Coords.), Derechos humanos de los grupos vulnerables. Red de Derechos Humanos y Educación Superior.

Münch, G. (2010). La religiosidad indígena en el obispado de Oaxaca durante la Colonia y sus proyecciones actuales. Anales de Antropología, 19(2), 185-205. http://dx.doi. org/10.22201/iia.24486221e.1982.2.16486

Peña Chivatá, C., Sierra-Zamora, P. A., \& Hoyos Rojas, J. C. (2019). La política de fronteras de Colombia ante las nuevas amenazas de seguridad y defensa. Revista Cientifica General José María Córdova, 17(28), 773-795. https://doi.org/10.21830/19006586.473

Pepinosa, H. E. (2012). Una mirada al concepto de justicia desde la cosmovisión indígena de los pastos. Revista de la Facultad de Derecho y Ciencias Políticas, 42(117), 481-514.

Pequeño, A. (2009). Violencia de género y mecanismos de resolución comunitaria en comunidades indígenas de la sierra ecuatoriana. En M. Lang, \& A. Kucia (Comps.), Mujeres indigenas y justicia ancestral. Flacso. 
Perafán, C. (1995). Sistemas jurídicos páez, kogi, wayúu y tule. Revista de Estudios Sociales, 1, 128-129. https://doi.org/10.7440/res1.1998.27

Plaza, C. (2001). Jurisdicción especial indígena: competencia. BIRA: Boletín del Instituto RivaAgüero, 28, 117-138.

Ramírez, S. (2005). Diversidad cultural y pluralismo jurídico: administración de justicia indígena. Iura Gentium, 1(1), 1-15.

Rojas, B., Sánchez, E., Roldán, R., \& Sánchez, M. (1993). Derechos e identidad. Los pueblos indígenas y negros en la Constitución Política de Colombia. Disloque.

Rueda Carvajal, C. E. (2008). El reconocimiento de la jurisdicción especial indígena dentro del sistema judicial nacional en Colombia. El debate de la coordinación. Estudios SocioJurídicos, 10(1), 339-374.

Sánchez, E. (2005). Reflexiones en torno de la jurisdicción especial indígena en Colombia. Revista del Instituto Interamericano de Derechos Humanos, 41, 227-250.

Sánchez,E.(2009).Larealizacióndel pluralismojurídicodetipoigualitarioenColombia.NuevaAntropología, 22(71), 31-49. http://www.scielo.org.mx/scielo.php?pid=S0185-06362009000200003\&script=sci_abstract

Stavenhagen, R. (1990). Derecho consuetudinario indígena en américa latina. En Entre la ley y la costumbre. Instituto Indigenista Interamericano (III) y el Instituto Interamericano de Derechos Humanos (IIDH).

Stavenhagen, R. (1995). Los derechos indígenas: nuevo enfoque del sistema internacional. Revista IIDH, 10, 39-64.

Unicef. (1989). Convención Sobre los Derechos del niño. https://www.ohchr.org/sp/professionalinterest/pages/crc.aspx

Villegas, M. (2014). Sistemas sancionatorios indígenas y derecho penal: ¿subsiste el az mapu? Politica Criminal, 9(17), 213-247. http://dx.doi.org/10.4067/S071833992014000100007

Vivar, M. E. (2015). La justicia indígena y su repercusión en el juzgamiento de conductas indebidas y la violación de los principios contemplados en la constitución de la República del Ecuador [Tesis de pregrado]. Universidad de Cuenca.

Wieviorka, M. (2003). Violencia y crueldad. Anales de la Cátedra Francisco Suárez, 37, 155-171. https://revistaseug.ugr.es/index.php/acfs/article/view/1089/1287

Yrigoyen, R. (2000). Reconocimiento constitucional del derecho indígena y la jurisdicción especial en los países andinos (Colombia, Perú, Bolivia, Ecuador). Revista Pena y Estado, 4. https://bit.ly/2ZEr66t

\section{Jurisprudencia}

Colombia, Corte Constitucional. (1993). Sentencia T-380. MP Eduardo Cifuentes Muñoz.

Colombia, Corte Constitucional. (1994). Sentencia T-254. MP Eduardo Cifuentes Muńoz.

Colombia, Corte Constitucional. (1996). Sentencia C-139. MP Carlos Gaviria Díaz. 
Colombia, Corte Constitucional. (1996). Sentencia T-349. MP Carlos Gaviria Díaz.

Colombia, Corte Constitucional. (1996). Sentencia T-496. MP Carlos Gaviria Díaz.

Colombia, Corte Constitucional. (1997). Sentencia T-523. MP Carlos Gaviria Díaz.

Colombia, Corte Constitucional. (2001). Sentencia T-1127. MP Jaime Araujo Rentería.

Colombia, Corte Constitucional. (2002). Sentencia C-370. MP Eduardo Montealegre Lynett.

Colombia, Corte Constitucional. (2019). Sentencia T-208. MP Carlos Bernal Pulido.

\section{Referencias normativas}

Colombia, Congreso de la República. (1990). Ley 52. Por la cual se establece la estructura orgánica Marco del Ministerio de Gobierno; se determinan las funciones de sus dependencias; se dictan otras disposiciones y se conceden unas facultades extraordinarias. Art 17.

Colombia, Congreso de la República. (2000). Ley 599. Por la cual se expide el código penal Colombiano. Art. 33.

Constitución Política de Colombia. (1991). Legis Editores (42 ed., 2019).

\section{Tratados internacionales}

ACNUDH. (1984). Convención contra la Tortura y Otros Tratos o Penas Crueles, Inhumanos o Degradantes, Adoptada y Abierta a la Firma, Ratificación y Adhesión por la Asamblea General en su Resolución 39/46, de 10 de diciembre. 